\title{
METODE BRACKETING EDMUN HUSSERL
}

\author{
Syamsul Amal \\ Fakultas Ushuluddin dan Dakwah IAIN Ambon \\ *)E-mail:syamsulamal@gmail.com
}

\begin{abstract}
This article intends to put forward the views phenomenology of Edmund Husserl, by using methods of desecaraiptive analysis of the data obtained in writing either of journals, books and articles obtained from the website, and blog. This study found that, first, intentional awareness is directed to the object that appears or appeared, without intentional object does not mean anything, and vice versa. Second, epoche or bracketing is the method used so that researchers can obtain the original data, by actively participating live the experience along with the living world, then did the reduction or containment or delay of assumptions, theories, knowledge, and even beliefs that may hamper researchers obtained data pure, by letting the objects speak for themselves. (Zurruk zu den zahen selbst). Religion is a manifestation of one's beliefs, to find out the essence of religious teachings that were understood then the method of bracketing is definite.
\end{abstract}

Keywords: phenomenology, Edmund Husserl, intentional, bracketing

\section{PENDAHULUAN}

Sidang tentang kasus "kopi bersianida" akhir-akhir begitu menyita perhatian masyarakat. Siding-demi sidang berlangsung tapi hakim belum juga menjatuhkan palu. Setiap orang yang menyaksikannya tentu telah memberikan berkomentar beragam. Sebagian mengatakan terdakwa pasti akan divonis berat sesuai hukum, tetapi sebagian lainnya masih sangsi apakah hakim akan menjatuhkan vonisnya. Ini adalah sebuah ilustrasi kecil mengenai apa yang akan dibahas dalam makalah ini. Bahwa fenomena muncul itu mengundang setiap orang berasumsi, penantian terhadap putusannya adalah keniscayaan.

Istilah fenomena yang seringkali didengar ternyata telah menjadi perbincangan para filosof dalam mengagas metode pengetahuan. Edmun Husserl (1859-1938) misal, sebagai penggagas arah baru dalam filsafat fenomelogi menyebutnya fenomena sebagai objek yang hadir dalam kesadaran. Metode fenomenologinya kemudian terkenal dan berpengaruh besar beberapa disiplin ilmu seperti sosiologi, Antropologipologi dan psikologi.
Istilah ini sebelumnya sudah diperkenalkan oleh Johann Heinrich Lambert (1728-1777), seorang filsuf Jerman dalam bukunya Neues Organon (1764). Sebelum Lambert, istilah fenomenologi juga pernah dikemukakan oleh filsuf-filsuf lainnya; Immanuel Kant (1724-1804) dan Georg Wilhelm Friedrich Hegel (1770-1831).

Immanuel Kant menggunakan istilah fenomenologi dalam karyanya Prinsip-Prinsip Pertama Metafisika (1786). Kant menyebutkan istilah fenomena sebagai lawan dari kata nomena. Nomena merupakan suatu kata yang sangat abstrak yang bagi Kant disebutkan tidak akan bisa dilihat oleh manusia. Namun, nomena bisa diketahui melalui fenomena. Sesuatu yang tidak terlihat bukan berarti tidak ada. Nomena dalam perspektif Kant menunjukkan suatu objek realitas yang tidak diketahui dan tidak tampak. ${ }^{1}$ Dalam perspektif ini tentu saja bisa disebutkan bahwa nomena hanya bisa dibaca melalui fenomena.

Selain itu, Hegel (1807) lalu memperluas pengertian fenomenologi dengan

${ }^{1}$ http://aidilaulya.com/2016/02/16/membacanomena-lgbti/ 8/23/2016; 20;16 
meru-muskannya sebagai ilmu mengenai pengalaman kesadaran, yakni suatu pemaparan dia-lektis perjalanan kesadaran kodrati menuju kepada pengetahuan yang sebenarnya. Fenomena menurut Hegel tidak lain merupakan penampakkan atau fenomena dari penge-tahuan inderawi: fenomena-fenomena merupakan manifestasi konkret dan historis dari perkembangan pikiran manusia. $^{2}$

Kemudian Hegel (1807) memperluas pengertian fenomenologi dengan merumuskannya sebagai ilmu mengenai pengalaman kesadaran, yakni suatu pemaparan dialektis perjalanan kesadaran kodrati menuju kepada pengetahuan yang sebenarnya. Fenome-nologi menunjukkan proses menjadi ilmu pengetahuan pada umumnya dan kemampuan mengetahui sebagai perjalanan jiwa lewat bentuk-bentuk atau gambaran kesadaran yang bertahap untuk sampai kepada pengetahuan mutlak.

Menurut Husserl fenomenologi tidak bias dilepaskan dengan Labenswelt (dunia kehidupan). Penyelidikan ini hendaknya menekankan watak intensional kesadaran, dan tanpa mengandalkan praduga-praduga konseptual dari ilmu-ilmu empiris. Fenomenologi merupakan metode dan filsafat. Sebagai metode, fenomenologi membentangkan langkah-langkah yang harus diambil sehingga kita sampai pada fenomena yang murni.

Fenomenologi mempelajari

dan melukiskan ciri-ciri intrinsic fenomen-fenomen sebagaimana fenomen-fenomen itu sendiri menyingkapkan diri kepada kesadaran. Kita harus bertolak dari subjek (manusia) serta kesadarannya dan berupaya untuk kembali kepada "kesadaran murni". Untuk mencapai bidang kesadaran murni, kita harus mem-

\footnotetext{
${ }^{2}$ Erstyn Gothique, Fenomenologi dan Hermeneutika: Sebuah Perbandingan; http://republicgothic. blogspot. co.id/2012/12/fenomenologi-dan-hermeneutikasebuah.html; dikutip 8/21/16;23;50
}

bebaskan diri dari pengalaman serta gambaran kehidupan sehari-hari.

Sebagai filsafat, fenomenologi menurut Husserl memberi pengetahuan yang perlu dan esensial mengenai apa yang ada. Dengan demikian, fenomenologi dapat dijelaskan sebagai metode kembali ke benda itu sendiri (Zurruk $\mathrm{Zu}$ den Sachen Selbt), dan ini disebabkan benda itu sendiri merupakan objek kesadaran langsung dalam bentuk yang murni.

Makalah ini mencoba mengulas kembali metode fenomenologi (bracketing) yang digagas oleh Edmun Husserl. Dengan mengemukakan fenomenologi sebagai filosofi, labenswelt, fenomenologi sebagai metode; bracketing, intentional, serta fenomenologi agama.

\section{KONSEPSI FENOMENOLOGI}

Istilah Fenomenologi berasal dari bahasa yunani, phenomenon, yaitu sesuatu yang tampak, yang terlihat karena berkecakupan. Dalam bahasa Indonesia biasa dipakai istilah gejala. $^{3}$ Data lain menyebutkan bahwa fenomenologi berasal dari bahasa Yunani: Phainestai yang artinya "menunjukkan" dan "menampakkan diri sendiri" 4 Secara istilah, fenomenologi adalah ilmu (logos) tentang apa yang tampak. Dengan kata lain fenome-nologi adalah suatu aliran yang membicarakan fenomena atau segala sesuatu yang tampak atau yang menampakkan diri. ${ }^{5}$

Berbeda dengan positivis yang mengumpulkan data, mencari korelasi dan fungsi, serta membuat hukum-hukum dan generalisasi. Fenomenolog bergerak di bidang yang pasti. yang menampakkan dirinya dilukiskan tanpa meninggalkan bidang evidensi

\footnotetext{
${ }^{3}$ https://www.academia.edu/7155053/pemikiran_ fenomenologi_menurut_edmund_husserl;/8/23/16;03;56 ${ }^{4} \mathrm{http}: / /$ nederindo.com/2012/04/konsepintensionalitas-dan-3-bentuk-reduksi-fenomenologiedmund-husserl/8/23/16;03;09

${ }^{5}$ K. Bertens, , Filsafat Barat Abad XX: InggrisJerman (Jakarta: Gramedia, 1981) h. 109
} 
yang langsung. Fenomenologi adalah suatu metode pemikiran, "a way of looking at things".

Fenomenologi diperkenalkan oleh Edmund Husserl (1859-1938), meski sebenarnya istilah tersebut telah digunakan oleh beberapa filsuf sebelumnya. Secara umum pandangan fenomenologi ini bisa dilihat pada dua posisi, yang pertama ia merupakan reaksi terhadap dominasi positivisme, dan yang kedua, sebenarnya sebagai kritik terhadap pemikiran kritisisme Immanuel Kant, terutama konsepnya tentang fenomenon-numenon.

Seperti kita telah ketahui, konsepsi Kant tentang proses pengetahuan manusia adalah suatu proses sintesa antara apa yang ia sebut dengan apriori dan aposteriori, yang pertama merupakan aktivitas rasio aktif dan dinamis dalam membangun, dan berfungsi sebagai bentuk (form) pengetahuan, sedang yang kedua merupakan terapan pengalaman yang berfungsi sebagai 'isi' (matter) pengetahuan, yang terdiri dari fenomena objek. Karena rasio bersifat aktif dalam mengkonstruksi fenomena menjadi pengetahuan sesuai dengan kategori-kategori rasio, maka pengetauan manusia tidak mungkin menjangkau noumena. ${ }^{6}$

Kant menggunakan kata fenomena untuk menunjukkan penampakan sesuatu dalam kesadaran, sedangkan noumena adalah realitas (das Ding an Sich) yang berada di luar kesadaran pengamat. Menurut Kant, manusia hanya dapat mengenal fenomena-fenomena yang nampak dalam kesadaraan, bukan noumena yaitu yaitu realitas di luar (berupa benda-benda atau atau nampak tetap menjadi objek kesadaran kita) yang kita kenal. Noumena yang selalu tetap menjadi teka-teki dan tinggal sebagai " $x$ " yang tidak dapat dikenal karena terselubung dari kesadaran.

Fenomena yang nampak dalam kesadaran kita ketika berhadapan dengan realitas (noumena) itulah yang kita kenal. Melihat warna biru, misalnya tidak lain adalah hasil cerapan indrawi yang membentuk pengalaman batin yang diakibatkan oleh sesuatu dari luar. Warna biru itu sendiri merupakan realitas yang tidak dikenal pada diri sendiri (in se). Ini berarti kesadaran kita tertutup dan terisolasi dari realitas. Demikianlah, Kant sebenarnya mengakui adanya realitas eksternal yang berada diluar diri manusia, yaitu sebuah realitas itu ia sebut das Ding an sich (objek pada dirinya sendiri) atau noumena.

\section{Konsep Lebenswelt: Dunia kehidupan}

Fenomenologi Husserl tidak telepas dari konsep Lebenswelt (yang biasanya diterjemahkan, “dunia-kehidupan”). Konsep ini penting artinya, sebagai usaha memper-luas konteks ilmu pengetahuan atau membuka jalur metodologi baru bagi ilmu-ilmu sosial serta untuk menyelamatkan subjek pengetahuan. Edmun Husserl, dalam bukunya termasyhur, The Crisis of European Science and Transcendental Phenome-nology, menyatakan bahwa konsep dunia-kehidupan merupakan konsep yang dapat menjadi dasar bagi (mengatasi) ilmu pengetahuan yang tengah mengalami krisis akibat ola pikir positivistik dan sainstistik itu. Katanya: "dunia-kehidupan adalah dasar makna yang dilupakan bagi ilmu pengetahuan". ${ }^{7}$

Dunia- kehidupan dalam pengertian Husserl bisa dipahami kurang lebih, dunia sebagaimana manusia menghayati dalam spontanitasnya, sebagai basis tindakan komunikasi antar subjek. Dunia-kehidupan ini adalah unsur-unsur sehari-hari yang membentuk kenyataan kita, yakni unsur dunia sehari-hari yang kita libati dan hidupi sebelum kita menteorikannya atau menrefleksikannya secara filosofis. Dunia- kehidupan memuat segala
${ }^{6}$ http://nederindo.com/2012/04/konsepintensionalitas-dan-3-bentuk-reduksi-fenomenologiedmund-husserl/ 8/23/16;03;59
${ }^{7}$ R. Bubner, Modern German Philosophy, (London: Cambridge University Press, 1981), p. 33 
orientasi yang kita andaikan begitu saja dan kita hayati pada tahap-tahap yang paling primer. Didalam kehidupan praktis kita, entah yang sederhan aentag yang sangat rumit, kita bergerak di dalam dunia yang sudah diselubungi dengan penafsiran dan kategori-kategori ilmu pengetahuan dan filsafat dan juga sedikit banyak penafsiran-penafsitran itu diwarnai oleh kepentingan-keentingan kita, situasi-situasi kehidupan kita, dan kebiasaan-kebiasaan kita. Kita telah melupakan dunia apa adanya, yaitu dunia-kehidupan, tempat berpijaknya segala bentuk penafsiran. Oleh karena itu semboyan Husserl; Zuruck zu Sachen selbt dimaksudkan sebagai usaha fenomenologis untuk menemukan kembali dunia-kehidupan itu.

Dunia-kehidupan sosial ini tak dapat diketahui begitu saja lewat observasi seperti dalam eksperimen ilmu-ilmu alam, melainkan terutama melalui pemahaman (verstehen). Apa yang ingin ditemukan dalam dunia-sosial adalah makna, bukan kausalitas yang niscaya. Tujuan ilmuan sosial mendekati wilayah observasinya adalah memahami makna (sinverstehen). Seorang ilmuan sosial, dalam hal ini, tidak lebih tahu dari pada para pelaku dalam dunia sosial itu. Oleh karena itu, dengan cara tertentu ia harus masuk kedalam dunia-kehidupan yang unsur-unsurnya ingin ia jelaskan itu. Untuk dapat men-jelaskannya, ia harus memahaminya. Untuk memahaminya, ia harus dapat berpartisipasi ke dalam proses yang menghasilkan dunia-kehidupan itu. Akhirnya, partisipasi itu mengandaikan bahwa ia sudah termasuk di dalam dunia-kehidupan itu.

Kontribusi dan tugas fenomenologi dalam hal ini adalah deskripsi atas sejarah lebenswelt tersebut untuk menemukan 'endapan makna' yang merekonstruksi kenyataan seharihari. Maka, meskipun pemahaman terhadap makna dilihat dari sudut inten-sionalitas (kesadaran) individu, namun 'akurasi' kebenarannya sangat ditentukan (atau mungkindijamin) oleh aspek intersubjektif. Dalam arti, sejauh mana 'endapan makna' yang ditemukan itu benar-benar direkonstruksi dari duniakehidupan sosial, di mana banyak subjek samasama melibati dan menghayati.

Demikianlah, dunia-kehidupan sosial merupakan sumbangan berharga dari fenomenologi, yang menempatkan fenomena sosial sebagai sistem simbol, yang harus dipahami dalam kerangka konteks sosio-kultur yang membangunnya. Ini artinya unsur subjek dilihat sebagai bagian tak terpisahkan dari proses terciptanya suatu ilmu pengeta-huan sekaligus mendapatkan dukungan metodologisnya.

\section{Metode Bracketing (Epoche)}

Seperti setelah disinggung sebelumnya, Husserl mengajukan konsepsi yang berbeda dengan para pendahulunya mengenai proses keilmuan. Tugas utama fenome-nologi menurut Husserl menjalin keterkaitan manusia dengan realitas. Bagi Husserl, realitas bukan sesuatu yang berbeda pada dirinya lepas dari manusia yang mengamati. Realitas itu mewujudkan diri atau menurut ungkapan Martin Heideger juga seorang fenomenolog: "sifat realitas itu membutuhkan keberadaan manusia". Noumena membu-tuhkan tempat tinggal (unterkunft) ruang untuk berada, ruang itu adalah manusia. ${ }^{8}$

$$
\text { Husserl menggunakan istilah }
$$

fenomenologi untuk menunjukkan apa yang nampak dalam kesadaran kita dengan membiarkannya termanifestasi apa adanya tanpa memasuk-kan kategori pikiran kita padanya atau menurut ungkapan Husserl: zuruck zu den sachen selbt (kembalilah pada realitas itu sendiri). Berbeda dengan Kant, Husserl menyatakan, bahwa apa yang disebut fenomena adalah realitas itu sendiri yang nampak setelah kesadaran kita cair dengan realitas. Fenomenologi Husserl justru bertujuan mencari

${ }^{8}$ http://muhammadhakim02.blogspot.co.id/2014/ 11/teori-model-fenomenologi-menurut-edmund.html; $8 / 23 / 2016 ; 03 ; 25$ 
yang esensial atau eidos (esensi) dari apa yang disebut fenomena. Metode yang digunakan untuk mencari yang esensial adalah dengan membiarkan fenomena itu berbicara sendiri tanpa dibarengi dengan prasangka (presuppositionlessness). Dalam hubungan ini Husserl menjelaskan:

"..that at first we shall put out of action the conviction we have been accepting up to now, including all our science. Let the idea guiding our meditation be at Cartesian idea of science that shall be established as radically as genuine, ultimately all-embracing science.",

(... yang pertama, kita harus menghilangkan dari tindakan kita semua keyakinan yang kita miliki sampai sekarang, termasuk semua pengetahuan kita. Biarkan ide itu menuntun semua meditasi kita pada pertama kalinya menjadi ide Cartesian mengenai sesuatu ilmu yang akan dikukuhkan secara radikal dan murni yang pada akhirnya merangkul semua isi pengetahuan).

Husserl dalam hal ini mengajukan metode epoche'. Kata epoche berasal dari bahsa Yunani, yang berarti: "menunda putusan" atau "mengosongkan diri dari keyakinan tertentu." Epoche bisa juga berarti tanda kurung (breaketing) terhadap yang diperoleh dari sesuatu fenomena yang tampil, tanpa memberikan putusan benar salahnya terlebih dahulu. Dalam hal ini Husserl mengatakan, bahwa epoche merupakan thesis of natural standpoints (tesis tentang pendirian yang natural), dalam arti bahwa fenomena yang tampil dalam kesadaran adalah benar-benar natural tanpa dicampuri oleh presupposisi pengamat.

$$
\text { Dapat }
$$

dikatakan

bahwa

fenomenologi berusaha mengungkap fenomena sebagai-mana adanya (to show it self) atau

${ }^{9}$ Edmund Husserl, Cartesian Meditation,(The Hague Martinus Nijhoff,1966) menurut penampakannya sendiri (veils itself), atau menurut penjelasan Elliston, "phenomenology then means... to let what shows itself be seen by itself and in terms of itself, just as it shows itself by and from itself." (fenomenologi dapat berarti: ... membiarkan apa yang menunjukkan dirinya sendiri dilihat melalui dirinya sendiri dan dalam batas-batas dirinya sendiri, sebagaimana ia menunjukkan dirinya melalui dan dari dirinya sendiri). Untuk ini Husserl menggunakan istilah "intensionalitas", yakni realitas yang menampakkan diri dalam kesadaran individu atau kesadaran intensional dalam menangkap 'fenomena apa adanya'.

Sebagaimana disinggung di atas, Husserl menggunakan istilah di fenomenologi untuk menunjukkan apa yang nampak dalam kesadaran kita dengan membiarkannya termanifestasi apa adanya atau menurut Husserl: zuruck zu den sachen selbt (kembalilah kepada realitas itu sendiri), ${ }^{10}$ bagi Husserl, apa yang disebut fenomena adalah realitas itu sendiri yang Nampak setelah kesadaran kita cair dengan realitas. Fenomenologi Husserl bertujuan mencari essensial atau eidos (esensi) metode yang digunakan untuk mencari yang essensial adalah dengan membiarkan fenomena itu berbicara sendiri tanap dibarengi dengan prasangka.

Konsep teknis yang diajukan Husserl adalah epoche (bracketing). Kata epoche berasal dari kata yunani, yang berarti: "menunda putusan" atau mengosongkan diri dari keyakinan tertentu. Metode epoche merupakan langkah-langkah, untuk mencapai essensi fenomena dengan menunda putusan lebih dulu. Selajutnya Husserl menyebutnya dengan eidetic vision atau membuat ide (ideation). Eidetic vision ini juga disebut "reduksi", yakni menyaring fenomena sampai ke eideosnya atau

${ }^{10}$ Heideger menulis:"...des wesen des sin dan menscenhenwesen brauch". Lihat Martin Heidger, Die Tecnik und die Kehre 
intisarinya. Hasil dari proses reduksi ini disebut wesenschau, artinya sampai pada hakikatnya. ${ }^{11}$

Dengan begitu, fenomenologi berusaha mengungkap fenomena sebagaimana adanya (to show it selft) menurut penampakkannya sendiri (veils it self), atau menurut penjelasan Elliston, "fenomenologi dapat berarti: membiarkan apa yang menunjukkan dirinya sendiri dilihat melalui dirinya dan dalam batas-batas dirinya sendiri, sebagaimana dia menunjukkan dirinya melalui dan melalui dirinya sendiri". Untuk ini Husserl menggunakan istilah "intensionalitas", yakni realitas yang menampakkan diri dalam kesadaran individu atau kesadaran intensional dalam menangkap "fenomena apa adanya".

Data yang lain menyebutkan bahwa Husserl membagi bracketing menjadi 4 tahap;

1. Method of historical bracketing; methode yang mengesampingkan aneka macam teori dan pandangan yang pernah kita terima dalam kehidupan sehari-hari.

2. Method of existensional bracketing; meninggalkan atau abstain terhadap semua keputusan.

3. Method of transcendental bracketing; mengolah data yang kita sadari menjadi gejala yang transcendental dalam kesadaran murni.

4. Method of eidetic reduction; mencari esensi fakta, menjadikan realitas menjadi esensi atau intisari realitas itu. $^{12}$ Dengan menerapkan empat metode apoche tersebut, seseorang akan sampai pada hakikat fenomena dari realitas yang dia amati.

Didalam proses berbagai pemikiran fenomenologi terdapat beberapa tahap berpikir yaitu Intensionalitas (keterarahan isi kesadaran) dan Reduksi. Sedangkan dalam fenomenologi pengalaman estetik terdapat beberapa pemahaman yang penting menuju refleksi,

\footnotetext{
${ }^{11}$ Antonio Barbosa da Silva, The phenomenology....,39

${ }^{12}$ https://www.britannica.com/topic/eideticreduction, di kutip 8/21/16;22;05
}

yaitu: imajenasi, persepsi, perasaan dan kebenaran. Analisis berdasarkan Intensionalitas dari proses kesadaran bila dibatasi pada kesadaran berikut korelasinya, dapat merupakan awal kemungkinan yang paling kritis untuk filsafat.

\section{Intensionalitas}

"Intensionalitas" merupakan konsep kunci filsafat Husserl. Intensionalitas adalah asumsi ontologis yang menyatakan bahwa esensi realitas dengan sendirinya menampakkan diri pada kesadaran intuitif subjek. Begitu juga sebaliknya, kesadaran subjek merupakan keinsyafan mendalam di tengah penampakan (kehadiran), esensi realitas. Kesadaran subjek dan esensi realitas menyatu secara intensional dalam kesadaran subjek.

Salah satu hal yang muncul sebagai hasil fenomenologi Husserl ialah perhatian baru untuk intensionalitas kesadaran. ${ }^{13}$ Kesadaran kita tidak dapat dibayangkan tanpa sesuatu yang disadari. Supaya ada kesadaran memang diandaikan tiga hal, yaitu bahwa ada suatu subyek yang terbuka untuk obyek-obyek yang ada. Fakta bahwa kesadaran selalu terarah kepada obyek-obyek disebut intensionalitas (dari kata "intendere" artinya "menuju ke"). Kiranya tidak tepat mengatakan bahwa kesadaran mempunyai "intensionalitas", karena kesadaran itu justru intensionalitas. Entah kita sungguh-sungguh melihat suatu pemandangan itu, bila kita masih menyadari perbedaan antara kedua kemungkinan ini maka kita tetap menyadari sesuatu. Kesadaran tidak pernah pasif melulu. Karena menyadari sesuatu berarti mengubah sesuatu. Hal yang disadari dijadikan sesuatu yang ada bagi saya. Kesadaran itu bukan berarti suatu cermin atau foto. Kesadaran itu suatu tindakan. Artinya terdapat interaksi antara tindakan kesadaran dengan obyek kesadaran. Namun interaksi ini tidak boleh

\footnotetext{
${ }^{13}$ Hamersma, Harry. Op.cit. hlm. 117.
} 
dianggap sebagai kerjasama antara dua unsur yang sama penting. Karena akhirnya, hanya ada kesadaran, obyek yang disadari itu hanyalah suatu ciptaan kesadaran.

Pengalaman subyek harus selalu dipandang sebagai pengalaman yang terlibat secara aktif dengan dunia. Kesadaran tidak tertutup dari dunia, tetapi selalu menuju, mengarah dan membuka pada dunia. Oleh karena itu kita tidak boleh memikirkan pengalaman dalam kesadaran manusia seperti obyek "dalam kardus".

Pengalaman bukan sebuah "celah" yang mana dunia, hadir terpisah darinya, menerobos masuk. Itu tidak sama halnya dengan menarik sesuatu yang asing ke dalam kesadaran. Pengalaman adalah pagelaran yang mana bagi saya, sosok yang mengalami, wujud yang dialami 'ada di sana' dan di sana sebagaimana adanya dengan seluruh muatannya dan modus berada di mana pengalaman sendiri. Lewat intensionalitas, yang melekatkannya. ${ }^{14}$

\section{Fenomenologi Agama}

Sehubungan dengan istilah fenomenologi agama, ${ }^{15}$ Richard C. Martin menyatakan, fenomenologi agama berusaha diterapkan pada manifestasi-manifestasi agama

${ }^{14}$ Adian, Donny Gahral. Op.cit. hal. 141.

${ }^{15}$ Istilah fenomenologi berasal dari bahasa Yunani phainomenon yang berarti menunjukkan (makna) dirinya sendiri atau apa yang tampak. Jadi fenomenologi berarti ilmu yang mempelajari apa yang tampak atau apa yang menampakkan diri. Pendekatan fenomenologi ini, diilhami oleh cara pendekatan filosofis yang dikembangkan oleh Edmund Husserl, seorang keturunan Yahudi yang lahir di Prosznits, Moravia pada tahun 1859. Bahasan lebih lanjut periksa K. Bertens, Filsafat Barat Kontemporer: Inggris Jerman (Jakarta: Gramedia, 2002), 104-115. Namun demikian, istilah fenomenologi agama digunakan sebelumnya oleh PD. Chantaphie de la Saussaye (1848-1920) ahli studi agama kebangsaan Belanda. Bahkan ia dianggap sebagai pendiri fenomenologi agama. Periksa Allen, "Phenomenology of Religion", 191. Bandingkan Ahmad Norma Permata, "Pendahuluan Editor", dalam Metodologi Studi Agama, ed. Ahmad Norma Permata (Yogyakarta: Pustaka Pelajar,2000), 20. melalui metode deskripsi murni dimana penilaian peneliti tentang nilai dan kebenaran data agama dibawah penyelidikan yang secara sengaja ditangguhkan (epoche), obyek ditangkap esensinya (eiditic vision) yang terletak di belakang fenomena keagamaan. ${ }^{16}$

Hampir senada dengan Martin, Dhavamony juga menyatakan bahwa fenomenologi agama tidak hanya menghasilkan suatu deskripsi mengenai fenomena yang dipelajari, tidak juga bermaksud menerangkan hakikat filosofis dari fenomena itu, sebab fenomenologi agama bukanlah deskriptif atau normatif belaka, namun, fenomenologi agama berusaha memberikan "makna lebih dalam" dari suatu fenomen religius, sebagaimana dihayati dan dialami oleh manusia-manusia religius.

Ahimsa putra memahami bahwa secara fenomenologis agama dapat didefinisikan sebagai sebuah kesadaran mengenai (a) adanya dunia yang berlawanan -gaib dan empiris-dan (b) bagaimana manusia sebagai bagian dunia empiris (c) dapat menjalin hubungan simbolik dengan dunia gaib tersebut.

Definisi di atas menekankan aspek kesadaran dalam fenomena agama karena aspek kesadaran inilah yang ditekankan oleh Husserl. Sebagai suatu kesadaran, agama bisa bersifat individual, bisa pula sosial atau kolektif. Ketika kajian agama yang dilakukan lebih mengarah pada kesadaran yang individual sifatnya, maka kajian tersebut akan dapat bertemu dengan kajian psikologi agama, sedang ketika kajian yang dilakukan lebih mengarah pada aspek sosialnya, maka kajian tersebut akan merupakan kajian sosiologi agama atau Antropologipologi agama, dengan perspektif fenomenologi. ${ }^{17}$

${ }^{16}$ Richard C. Martin, "Islam dan Studi Agama", dalam Richard C. Martin (ed.), Pendekatan Kajian Islam dalam Studi Agama, ter. Zakiyuddin Bhaidawy (Surakarta: Muhammadiyah University Press UMS, 2002), 8 .

${ }^{17}$ Heddy Shri Ahimsa-Putra, Pendekatan Fenomenologi untuk Memahami Agama, Heddy Shri 
Sebagai sebuah kesadaran individual, maka dengan sendirinya "agama" tersebut akan merupakan suatu kesadaran yang sangat pribadi, yang tidak dimiliki oleh individu-individu yang lain. Deskripsi fenomenologis agama yang bersifat individual ini akan menekankan kesadaran-kesadaran, pengetahuanpengetahuan, pandangan-pandangan individual, yang khas sifatnya, yang kemudian mendorong munculnya perilaku-perilaku khas pula,yang individual.Sebagai sebuah kesadaran kolektif, maka "agama" akan merupakan sebuah kesadaran yang dimiliki bersama, sebuah kesadaran yang unsure-unsurnya dimiliki oleh banyak individu. Deskripsi fenomenologis agama pada dimensi kolektifnya ini akan menekankan pada kesadaran-kesadaran, pengetahuan-pengetahuan, pandanganpandangan yang bersifat kolektif, intersubjektif, yang mendorong munculnya perilaku-perilaku kolektif pula, yang menunjukkan adanya suatu 'umat', jamaah, dari agama tersebut.

Dengan demikian dapat ditegaskan; pertama, fenomenologi agama berusaha memperoleh gambaran yang lebih utuh tentang struktur fundamental atau esensi dari keberagamaan manusia secara umum (universal, transendental, inklusif) dan bukannya gambarara. keberagamaan manusia yang bersifat partikular eksklusif. Kedua, fenomeno-logi agama berusaha mengembalikan studi agama yang bersifat historis empiris pada pangkalannya agar tidak terlalu jauh melampaui batas kewenangannya. Ketiga, fenome-nologi agama berusaha untuk bersikap netral.

Menurut penulis, apa yang menjadb. gagasan Husserl adalah sesuatu yang fenomenal. Metode fenomenologinya (epoche) bukan hanya telah menginspirasi sosio-logi, Antropologipologi dan psikologi, tetapi kini

Ahimsa Putra, Walisongo, Volume 20, Nomor 2, November 2012 , h, 271 metodenya merupakan hal yang niscaya bagi para peneliti di bidangnya.

Menurut Thomas Kuhn, bahwa pada saat sebuah paradigm akan mapan maka kemudian paradigma yang baru akan dating untuk menggantikannya dengan yang baru. Fenomenologi Husserl bukanlah merupakan konsep final, salah satu yang perlu dibahas lebih lanjut adalah bahwa penelitian fenomenologi tidak dapat menghindari subjektifitas peneliti, bagaimanapun ia berusaha untuk tidak mengintervensi objektifikasi yang dilaku-kan. Hal itu karena peneliti adalah sosok pemberi nilai, interpreter atau penafsir dari objek yang menampakkan diri. Tetapi itupun bukan berarti hal itu tidak dapat dilakukan.

Menurut Derrida kita selalu cenderung untuk melepaskan teks dari konteksnya. Satu term tertentu kita lepaskan dari konteks (dari jejaknya) dan hadir sebagai makna final. Inilah yang Derrida sebut sebagai logosentrisme. Yaitu, kecenderungan untuk mengacu kepada suatu metafisika tertentu, suatu kehadiran objek absolut tertentu. Dengan metode dekonstruksi, Derrida ingin membuat kita kritis terhadap teks.

\section{KESIMPULAN}

Fenomenologi Husserl adalah pengetahuan tentang segala yang nampak atau yang hadir dalam kesadaran. Kesadaran yang disebut dengan Intentional adalah kesadaran yang terarah kepada objek yang menampakkan diri. Kesadaran tanpa objek tidak akan bermakna apa-apa, demikian pula sebaliknya. Artinya kesadaran selalu bersama dengan fenomenanya

Bracketing atau epoche adalah metode penundaan atau pengurungan dari semua persepsi, asumis, teori, budaya dan agama, agar pengetahuan bisa memperoleh pengetahuan sejati. Proses objektifikasi ini dimaksudkan agar terhindar dari bias dan distorsi dalam pemaknaan, ini yang disebut dengan pengetahuan tanpa presupposisi. Selain itu agar 
fenomena yang hadir dalam kesadaran tidak terkontaminasi oleh hal-hal di luar dirinya.

\section{Rekomendasi}

Penelitian ini tentu belum dapat dikatakan lengkap dan sempurna, karena itu penulis berharap penelitian yang bertema sama dapat melengkapi, menyem-purnakan artikel ini. Bagi perkembangan studi agama studi metode pengetahuan seperti ini diperlukan menambah khazanah keilmuan.

\section{DAFTAR PUSTAKA}

Adian, Donny Gahral. 2002. Pilar-pilar Filsafat Kontemporer. Yogyakarta: Jalasutra.

Adian, Donny Gahral. 2005. Percik Pemikiran Kontemporer: Sebuah Pengantar Komprehensif. Yogyakarta: Jalasutra.

Afandi, Abdullah Khozin. Fenomenologi. Int. (http://akhozinaffandi.blogspot.com /2010/02/ fenomenologi. html/diakses 20 Januari 2011)

Ahimsa-Putra. 1985. Etnosains dan Etnometodologi, Sebuah Perbandingan. Majalah Ilmu-ilmu Sosial Indonesia, Jilid XII Nomor 2, hlm.103-133. Jakarta: LIPI.

Bleicher, Josef. 2003. Hermeneutika Kontemporer. Yogyakarta: Fajar Pustaka Baru.

Bagus, Lorens. 1996. Kamus Filsafat. Jakarta: Gramedia.

Delgaauw, Bernard. 2001. Filsafat Abad 20, terj. Soejono Soemargono. Yogyakarta: Tiara Wacana.

Eagleton, Terry. 2006. Teori Sastra: Sebuah Pengantar Komprehensif, terj. Harfiah. Yogyakarta: Jalasutra.

Hadiwijono, Hasan. 1993. Sari Sejarah Filsafat Barat 2, Cet. Ke 9. Yogyakarta: Kanisius

Jazim Hamidi. 2005. Hermeneutika Hukum. Yogyakarta: UII Press.

Kuswarno, Engkus. Fenomenologi: Metode Penelitian Kualitati. (http://id.shvoong.com /books/ dictionary/1967914-fenomenologimetode-penelitian-kualitatif/ diakses tanggal 19 Januari 2010)

Muhadjir, Noeng. 1998. Filsafat Ilmu. Yogyakarta: Reka Sarasin.

Muslih, Moh.. 2005. Filsafat Ilmu: Kajian Atas Asumsi Dasar, Paradigma dan Kerangka Teori Ilmu Pengetahuan, Yogyakarta: Belukar.

Palmer, Richard E. 2005. Hermeneutika: Teori Baru Mengenai Interpretasi, Terj. Masnur Heri Damanhuri Muhammad, Yogyakarta: Pustaka Pelajar.

Poespoprodjo, W. 2004. Hermeneutika, Bandung: Pustaka Setia.

Raharjo, Mudjia. 2008. Dasar-dasar Hermeneutika antara Intersionalisme dan Gadamerian, Jogjakarta: ArRuzmedia.

Raharjo, Mudjia. Hermeneutika. Apa Manfaatnya?

(http://mudjiarahardjo.com/ artikel/103hermeneutika-apa-manfaatnya.html diakses pada 22 Januari 2011)

Suryaman, Oni. 2005. Hermeneutika, Selayang Pandang. Int., (http://id.wordpress.com/tag /hermeneutika/, diakses tanggal 20 Januari 2010)

Sutrisno, et.al.. 2005. Para Filusuf Penentu Gerak Zaman, Yogyakarta: Kanisius.

Sutrisno, Mudji. 2004. "Rumitnya Pencarian Diri Kultural" dalam Hermeneutika Pasca kolonial: Soal Identitas. Mudji Sutrisno dan Hendar Putranto (editor), Yogyakarta: Yayasan Kanisius.

Supriyono, J. 2004. "Mencari Identitas Kultur Keindonesiaan," dalam Hermeneutika Pascakolonial: Soal Identitas. Mudji Sutrisno dan Hendar Putranto (ed.), Yogyakarta: Yayasan Kanisius.

Titus, 1984. Persoalan-Persoalan Filsafat. Terj.

M. Rasyidi, Jakarta: Bulan Bintang. 
Wuisman, J.J.J.M. 1996. Penelitian Ilmu-Ilmu

Sosial Jilid I: Asas-Asas. Jakarta: Lembaga Penerbit FE-UI.

Ahmad Norma Permata, "Pendahuluan Editor", dalam Metodologi Studi Agama, ed. Ahmad Norma Permata (Yogyakarta: Pustaka Pelajar,2000)

Richard C. Martin, "Islam dan Studi Agama", dalam Richard C. Martin (ed.), Pendekatan Kajian Islam dalam Studi Agama, ter. Zakiyuddin Bhaidawy (Surakarta: Muhammadiyah University Press UMS, 2002)

Heddy Shri Ahimsa-Putra, Pendekatan Fenomenologi untuk Memahami Agama, Heddy Shri Ahimsa Putra, Walisongo, Volume 20, Nomor 2, November 2012.

Erstyn Gothique, Fenomenologi dan Hermeneutika: Sebuah Perbandingan; http://republicgothic. blogspot. co.id/2012/12/fenomenologi-danhermeneutika-sebuah.html; dikutip $8 / 21 / 16 ; 23 ; 50$

K. Bertens, Filsafat Barat dalam Abad XX, Jakarta: PT. Gramedia, 1981

Aholiab Watloly, 2001, Tanggungjawab Pengetahuan, Kanisius, Yogyakarta

Shofiyullah Mz, Fenomenologi Edmund Husserl (Suatu Pendekatan

MemahamiKetegangan Religiusitas), Jurnal Ilmu-Ilmu Ushuluddin Esensia, Vol. 3, No. 2, Juli, 2002

Hardiansyah A, Teori Pengetahuan Edmund Husserl, Jurnal Substantia Vol. 15, No. 2, Oktober 2013

http://fahmyzone.blogspot.co.id/2012/09/fenom enologi-edmund-husserl.html?m=1 di akses 8/21/16 21;58

http://amrinarose13.blogspot.co.id/2013/03/feno menologi.html di akses 8/21/16 21:56

http://satrioarismunandar6.blogspot.co.id/2009/ 06/fenomenologi-sebagai-sebuahmetode.html di akses $8 / 21 / 19 ; 22 ; 01$

http://www.kompasiana.com/www.antosriady.c om/fenomenologi-edmund-husserl_ 552e10066ea834 622e8b45b1 di akses 8/21/16; 22;04

http://fahmyzone.blogspot.co.id/2012/09/fenom enologi-edmund-husserl.html $\mathrm{m}=1$ dikutip 8/21/16 16:29

https://www.britannica.com/topic/eideticreduction, di kutip 8/21/16; 22; 05

http://www.ilmupsikologi.com/2015/08/filsafateksistensialisme-danfenomenologi.html, di kutip 8/21/16; 22; 10

http://agengwahyudi.blogspot.co.id/2015/10/eks istensialisme-dan-fenomenologi.html, dikutip 8/21/16; 22;13

http://fahmyzone.blogspot.co.id/2012/09/fenom enologi-edmund-husserl.html? $\mathrm{m}=1$; dikutip 8/21/16; 22;15

http://gumuksantren.blogspot.co.id/2014/11/ed mund-husserl-dan-pemikirannya.html; dikutip 8/21/16;22;15

http://zakkifuad.blogspot.co.id/2010/03/makalah .html; dikutip 8/21/16; 22;18

https://zainabzilullah.wordpress.com/2013/01/2 0/pemikiran-fenomenologi-menurutedmund-husserl/ dikutip; 8/21/16; $22 ; 21$

https://www.academia.edu/7939990/Pembedaan _Ontologis_dan_Pergulatan_Dasein_dal am_Mendekati_Ada_Dasar_Pemikiran_ Martin_Heidegger.

Muslih, Mohammad, Filsafat Ilmu, (Yogyakarta: Belukar, 2004)

Zubaidi ,Sujiat, dan Muslih, Mohammad, Kritik Epistemologi dan Model Pembacaan Kontemporer, (Yogyakarta: LESFI,2013)

Muhammad

Muslih,Filsafat

Ilmu,Belukar,Yogyakarta

K. Bertens, , Filsafat Barat Abad XX: InggrisJerman (Jakarta: Gramedia, 1981)

Doni Gahral Adian, Pilar Pilar Filasafat Kontemporer, Jogjakarta: Jala Sutra, 2002 
Sujiat Zubaidi-Mohammad Muslih kritik epistemologi Yogyakarta.

Edmund Husserl, Cartesian Meditation,(The Hague Martinus Nijhoff,1966)

Lihat R. Bubner, Modern German Philosophy, (London: Cambridge University Press, 1981.

Jan Hendrik raper, Pengantar Filsafat, (Yogyakarta: pustaka filsafat, 2010)

Fedrick Elliston, "phenomenology Reinterpreted: from Husserl to heidger" dalam philosophy today, vol. xxi, no 1977 